\title{
Repeated muscle glycogen supercompensation with four days' recovery between exhaustive exercise
}

Thomas M. Doering ${ }^{\mathrm{ab}}$, Gregory R. Cox ${ }^{\mathrm{a}}$, José L. Areta ${ }^{\mathrm{c}}$, Vernon G. Coffey ${ }^{\mathrm{a}}$

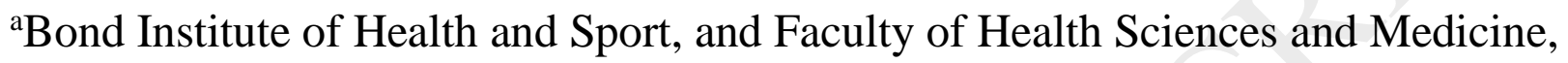
Bond University, QLD, Australia.

${ }^{\mathrm{b}}$ School of Allied Health Sciences, Griffith University, QLD, Australia. 'School of Sport and Exercise Sciences, Liverpool John Moores University, Liverpool, United Kingdom.

*Corresponding author: A/Professor Vernon G. Coffey, Faculty of Health Sciences and Medicine, Bond University, Gold Coast, QLD 4226 Australia. , Email: vcoffey@bond.edu.au
Abstract
Objectives: to determine if a $4 \mathrm{~d}$ period of high carbohydrate intake can supercompensate muscle glycogen and exercise work capacity on back-to-back occasions. 
Design: seven trained cyclists ( 6 male, $\mathrm{VO}_{2}$ peak: $\left.57 \pm 4 \mathrm{~mL} \cdot \mathrm{kg}^{-1} \cdot \mathrm{min}^{-1}\right)$ completed a 9-d experimental period, consisting of three intermittent exhaustive cycling trials on days 1 (trial 1), 5 (trial 2) and 9 (trial 3). Following trial 1 cyclists were fed a high carbohydrate diet $\left(\sim 10 \mathrm{~g} \cdot \mathrm{kg}^{-1} \cdot \mathrm{day}^{-1}\right)$ for eight days to assess their capacity to repeatedly supercompensate muscle glycogen with 4 d recovery.

Methods: a resting muscle biopsy was obtained prior to each trial consisting of 2 min work intervals (90-60\% peak power output) interspersed with 2 min recovery (40\% peak power output) repeated until exhaustion. Each $72-\mathrm{h}$ period between trial days included two days of low volume cycling and a rest day. Resting muscle glycogen and total work completed was determined for each trial day.

Results: baseline muscle glycogen on day $1\left(583.6 \pm 111.0 \mathrm{mmol} \cdot \mathrm{kg}^{-1}\right.$ dry mass $)$ was supercompensated on day $5\left(835.1 \pm 112.8 \mathrm{mmol} \cdot \mathrm{kg}^{-1}\right.$ dry mass; $\mathrm{p}=0.04, \mathrm{~d}$ $=2.25)$ and again on day $9\left(848.3 \pm 111.4 \mathrm{mmol} \cdot \mathrm{kg}^{-1}\right.$ dry mass; $\left.\mathrm{p}=0.01, \mathrm{~d}=2.38\right)$. Total cycling work capacity increased from trial 1 to trial $2\left(+8.7 \pm 5.4 \mathrm{~kJ} \cdot \mathrm{kg}^{-1} ; \mathrm{p}\right.$ $=0.01 ; \mathrm{d}=1.41) ;$ a large effect was observed in trial 3 compared to trial $1(+6.4$ $\left.\pm 6.8 \mathrm{~kJ} \cdot \mathrm{kg}^{-1} ; \mathrm{p}=0.10 ; \mathrm{d}=1.10\right)$.

Conclusions: a $4 \mathrm{~d}$ high carbohydrate feeding strategy is sufficient to repeatedly supercompensate muscle glycogen content following exhaustive exercise and results in enhanced work capacity. 
Keywords: aerobic exercise, athletic performance, carbohydrate loading, cycling.

\section{Introduction}

The relationship between dietary carbohydrate $(\mathrm{CHO})$ intake and skeletal muscle glycogen content has been recognised for over half a century. Pioneering work from the 1960's demonstrated that glycogen depletion concomitant with a high CHO diet over subsequent days resulted in an enhanced glycogen storage ${ }^{1}$. These data were the foundation for studies elucidating the relationship between dietary CHO intake and muscle glycogen concentrations ${ }^{2}$, exercise capacity ${ }^{3}$ and performance ${ }^{4}$. The use of stable isotopes in later years not only confirmed an increased reliance on carbohydrate oxidation with increasing exercise intensity, but also highlighted the crucial contribution of endogenous $\mathrm{CHO}$ to exercise greater than $\sim 85 \%$ of $\mathrm{VO}_{2}$ peak $^{5,6}$.

Carbohydrate loading achieved through high dietary $\mathrm{CHO}$ intake has been shown to promote skeletal muscle glycogen supercompensation and enhance prolonged (>90 min) endurance exercise performance in laboratory ${ }^{7}$ and field ${ }^{4}$ settings. Current recommendations suggest a $36-48 \mathrm{~h}$ period of high $\mathrm{CHO}$ feeding at $\sim 8-12 \mathrm{~g} \cdot \mathrm{kg}^{-1} \cdot \mathrm{day}^{-1}$ is sufficient to supercompensate muscle glycogen stores during a taper period ${ }^{8-10}$. However, despite the potential performance benefits of 
high pre-exercise $\mathrm{CHO}$ intakes, the congested competition schedules of professional athletes of many team sports and cycling in various formats ${ }^{11}$ including one-day classics, often limits the time between events and removes the opportunity for a traditional taper. In such a scenario, there is a paucity of data available on the capacity to supercompensate muscle glycogen twice in quick succession; i.e., repeatedly CHO loading for competitions separated by 3-4 days.

To date, a single study has examined the efficacy of "back-to-back" carbohydrate loading to achieve repeated muscle glycogen supercompensation ${ }^{12}$. McInerney and colleagues ${ }^{12}$ determined the capacity of well-trained male cyclists to supercompensate muscle glycogen prior to consecutive exhaustive exercise trials separated by $48 \mathrm{~h}$ recovery. They showed that with very high CHO intakes (12 $\left.\mathrm{g} \cdot \mathrm{kg}^{-1} \cdot \mathrm{day}^{-1}\right)$ throughout the experimental period, participants were able to supercompensate muscle glycogen once, but not on a second occasion when a $48 \mathrm{~h}$ recovery or "turnaround time" was available. Interestingly, Bussau and colleagues $^{13}$ have shown well-trained cyclists can supercompensate muscle glycogen in just $24 \mathrm{~h}$; thus, while the mechanisms underpinning the inability to repeatedly supercompensate muscle glycogen remain unclear, the interaction between days of recovery following repeated exhaustive exercise, the amount of $\mathrm{CHO}$ consumed, and the fate of ingested $\mathrm{CHO}$ appear to dictate the physiological 
and performance outcomes if repeated muscle glycogen supercompensation is desired.

Accordingly, the aim of the present study was to determine if extending the CHO loading period to $4 \mathrm{~d}$ between exhaustive exercise trials would enable "backto-back" muscle glycogen supercompensation in trained athletes. We hypothesised that a 4-day duration of higher total $\mathrm{CHO}$ intake between trials would augment the capacity for glycogen storage enabling repeated muscle glycogen supercompensation and enhanced performance.

\section{Methods}

Six male and one female cyclist completed the study $\left(\mathrm{n}=7,37 \pm 6 \mathrm{y}, \mathrm{VO}_{2}\right.$ peak: 56.8 $\pm 3.7 \mathrm{~mL} \cdot \mathrm{kg}^{-1} \cdot \mathrm{min}^{-1}$, peak power output (PPO): $323 \pm 36 \mathrm{~W}, 76.1 \pm 10.0 \mathrm{~kg}, 177.8$ $\pm 6.2 \mathrm{~cm})$. All participants reported a consistent training volume $\left(10.1 \pm 3.0 \mathrm{~h} \cdot \mathrm{w}^{-1}\right)$ for at least eight weeks prior to participation. The study was approved by Bond University's Human Research Ethics Committee and participants provided written informed consent prior to the study.

Participants initially visited the laboratory for preliminary testing and familiarisation, and provided a completed $3 \mathrm{~d}$ dietary record. Height and body mass was recorded (WM204, Wedderburn, Australia) and mass at this time-point was used for dietary prescription. Subsequently, a graded exercise test ${ }^{14}$ was 
completed to determine PPO for steady state (SS) cycling and trial workload prescription. Testing was conducted on an Excalibur Sport cycle ergometer (Lode, Groningen, Netherlands) and expiratory gasses were continuously monitored on a metabolic cart calibrated to manufacturer's instructions (CosMed, Rome, Italy). $\mathrm{VO}_{2}$ peak was deemed as the highest rate of oxygen consumption recorded over a $30 \mathrm{~s}$ average. Participants then undertook a $\sim 60 \mathrm{~min}$ familiarisation of the trial day protocol on the same Wattbike Pro cycling ergometer that was to be used in each trial (Wattbike Ltd, Nottingham, UK).

Seven ( \pm 2 ) days later participants commenced a $48 \mathrm{~h}$ exercise and $24 \mathrm{~h}$ dietary standardisation. Two days prior to cycling trial 1, participants completed a standardised SS cycling bout between 58 and 63\% PPO for 60-90 min. SS cycling bouts were also completed throughout the experimental period on days 2, 3, 6 and 7. All SS cycling bouts during the study were undertaken on the same habitual road training circuit matched within-participant, and a pedal-based power meter system was fitted to each participant's bicycle for training prescription and load monitoring (Assioma Uno, Favero Electronics, Arcade TV, Italy). One day prior to cycling trial 1 , participants were provided with a diet containing $5 \mathrm{~g} \cdot \mathrm{kg}^{-1} \mathrm{CHO}$. A continuous glucose monitor (CGM; iPro2; Medtronic, Northridge, CA, USA) was also inserted into the abdominal region, and a second CGM was inserted on day 4 of the experimental period. Participants recorded blood glucose concentrations 
from capillary blood (Abbott, IL USA) prior to each meal and sleep for CGM calibration. Seventy-two-hour area under the curve (AUC) was determined for the three days preceding trial 2 and 3, during $\mathrm{CHO}$ load 1 and 2, respectively. Due to technical difficulties CGM data are $\mathrm{n}=6$. Following the $48 \mathrm{~h}$ standardisation period participants commenced the $9 \mathrm{~d}$ experimental period consisting of three cycling trials on days 1, 5 and 9 (Figure 1).

On the morning of each cycling trial, participants reported to the laboratory (0600) after an overnight fast and a resting skeletal muscle biopsy was obtained from the vastus lateralis under local anaesthetic (1\% xylocaine) using a $5 \mathrm{~mm}$ Bergstrom needle modified with manual suction. Body mass was measured and participants completed a 10 min warm up at $40 \%$ PPO. Trials consisted of 2 min intervals at a 1:1 work-recovery ratio with heart rate $(\mathrm{HR})$ recorded continuously (Polar H10, Polar Electro, Finland). Work intervals initially corresponded to a mechanical workload of $90 \%$ PPO, and all recovery intervals were $40 \%$ PPO. Participants completed as many repetitions as possible until they could no longer maintain the prescribed workload (mean interval workload less than $3 \mathrm{~W}$ from prescribed); mechanical workload was then decreased by $10 \%$. This process was repeated at workloads of 80,70 and $60 \%$ PPO. When a workload of $60 \%$ PPO could no longer be maintained the trial was terminated. Blood glucose was measured immediately post-exercise, and athletes were subsequently fed a meal 
containing $2 \mathrm{~g} \cdot \mathrm{kg}^{-1} \mathrm{CHO}$ within $15 \mathrm{~min}$ of exercise cessation. Total work was calculated as the sum of all completed/attempted intervals inclusive of recovery bouts and expressed relative to body mass recorded on that day $\left(\mathrm{kJ} \cdot \mathrm{kg}^{-1}\right)$. Work done at each workload was calculated as the sum of only fully completed intervals, excluding recovery work. All exercise testing bouts were completed under standard laboratory conditions $\left(22^{\circ} \mathrm{C}\right)$ on the same cycle ergometer. At the completion of trial 1, participants consumed a high CHO diet $\left(\sim 10 \mathrm{~g} \cdot \mathrm{kg}^{-1} \cdot\right.$ day $\left.^{-1}\right)$ for the next eight days.

All meals and snacks were provided to participants and all foods were weighed prior to packaging for estimation of consumed CHO (Foodworks 7.0, Xyris, Australia). Participants were instructed to consume only foods provided and complete only exercise associated with the study; both were verified by daily food checklists and training diaries, respectively. Participants were instructed to consume foods as three main meals as prescribed, with additional foods consumed ad libitum but replicated on a daily basis. Final adjustments were made to the nutrient analysis for any foods omitted by participants. Training diaries recorded session rating of perceived exertion (sRPE) $)^{15}$ for SS cycling bouts, and data files from participant's global positioning systems were received daily to quantify

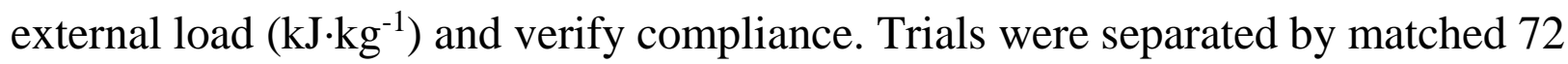
$\mathrm{h}$ periods consisting of the same prescribed low intensity SS cycling bout (as in the 
standardisation period) for two days followed by one rest day; thus, both training and diet from days 1-4 (CHO load 1, prior to trial 2) were replicated in days 5-8 (Figure 1).

Muscle glycogen concentration was determined according to the acid hydrolysis method ${ }^{16,17}$ with glucose concentration quantified using a commercially available kit (GLUC-HK, Randox Laboratories, Antrim, UK). Glycogen concentration ( $\mathrm{mmol} \cdot \mathrm{kg}^{-1}$ dry mass $[\mathrm{DM}]$ ) was then calculated and the mean of replicates used for data analysis. The $\mathrm{CV}$ of glycogen replicates was $5.9 \pm 6.0 \%$ (mean $\pm \mathrm{SD}$ ).

Data were analysed using one-way repeated measures analysis of variance and Tukey's multiple comparisons test was used for trial-to-trial comparisons. Paired t-tests were used to compare $72 \mathrm{~h}$ AUC values from interstitial glucose traces. Normality was confirmed by Shapiro-Wilk test and alpha was 0.05 . Cohen's d effect sizes were used to determine the magnitude of differences with threshold values for small, moderate and large effects $0.2,0.5$ and 0.8 , respectively. All statistical analyses were conducted in GraphPad Prism 7.03 (GraphPad software, CA USA) and data are mean \pm standard deviation.

\section{Results}


Participants' reported energy intake was $151.0 \pm 24.0 \mathrm{~kJ} \cdot \mathrm{kg}^{-1}$, containing $3.7 \pm 0.8$ $\mathrm{g} \cdot \mathrm{kg}^{-1} \mathrm{CHO}$. In the $24 \mathrm{~h}$ prior to cycling trial 1 participants consumed $137.4 \pm 6.4$ $\mathrm{kJ} \cdot \mathrm{kg}^{-1}$, containing $5.2 \pm 0.1 \mathrm{~g} \cdot \mathrm{kg}^{-1} \mathrm{CHO}$ in the provided standardised diet. Over the following eight-days, participants consumed a daily mean energy intake of 248.2 $\pm 9.7 \mathrm{~kJ} \cdot \mathrm{kg}^{-1}$ with mean macronutrient intakes of $10.6 \pm 0.4 \mathrm{~g} \cdot \mathrm{kg}^{-1} \mathrm{CHO}(0.3 \pm 0.1$ $\mathrm{g} \cdot \mathrm{kg}^{-1}$ fibre), $1.6 \pm 0.1 \mathrm{~g} \cdot \mathrm{kg}^{-1}$ protein and $1.0 \pm 0.1 \mathrm{~g} \cdot \mathrm{kg}^{-1}$ fat. Small daily variations in consumed $\mathrm{CHO}$ and energy intake were apparent with $\mathrm{CHO}$ intake higher on day $7\left(10.8 \pm 0.4 \mathrm{~g} \cdot \mathrm{kg}^{-1}\right)$ compared to days 1,2 and 4 (range of mean data: 10.4$\left.10.5 \mathrm{~g} \cdot \mathrm{kg}^{-1}, \mathrm{p}<0.05\right)$. Total energy was also lower on day $1\left(241.1 \pm 9.4 \mathrm{~kJ} \cdot \mathrm{kg}^{-1}\right)$ compared to days $2,4,6,7$ and $8\left(249.3-252.1 \mathrm{~kJ} \cdot \mathrm{kg}^{-1}, \mathrm{p}<0.05\right)$, and on day 5 $\left(243.2 \pm 10.7 \mathrm{~kJ} \cdot \mathrm{kg}^{-1}\right)$ compared with days 6 and $8\left(252.1-252.2 \mathrm{~kJ} \cdot \mathrm{kg}^{-1}, \mathrm{p}<0.05\right)$. There was a main effect of trial for muscle glycogen concentration (Figure 2A). Baseline muscle glycogen at trial $1\left(583.6 \pm 111.0 \mathrm{mmol} \cdot \mathrm{kg}^{-1} \mathrm{DM}\right)$ was increased prior to trial $2\left(835.1 \pm 112.8 \mathrm{mmol} \cdot \mathrm{kg}^{-1} \mathrm{DM}, \mathrm{p}=0.04, \mathrm{~d}=2.25\right)$ and trial $3\left(848.3 \pm 111.4 \mathrm{mmol} \cdot \mathrm{kg}^{-1} \mathrm{DM}, \mathrm{p}=0.01, \mathrm{~d}=2.38\right)$. There was also a main effect of trial for total work capacity (Figure 2B) and trial/cycling duration. Work capacity and cycling duration in trial $1\left(25.3 \pm 6.1 \mathrm{~kJ} \cdot \mathrm{kg}^{-1} ; 169.1 \pm 43.8 \mathrm{~min}\right)$ was increased in trial $2\left(34.0 \pm .6 .2 \mathrm{~kJ} \cdot \mathrm{kg}^{-1}, \mathrm{p}=0.01, \mathrm{~d}=1.41 ; 226.6 \pm 31.7 \mathrm{~min}, \mathrm{p}<0.01, \mathrm{~d}=1.50\right)$; a large but non-significant effect was evident in trial $3\left(31.7 \pm 5.5 \mathrm{~kJ} \cdot \mathrm{kg}^{-1}, \mathrm{p}=0.10\right.$, 
$\mathrm{d}=1.10 ; 208.0 \pm 22.4 \min , \mathrm{p}=0.12, \mathrm{~d}=1.12$ ). There was a modest decrease in cycling work capacity between trials 2 and 3 only evident as a small effect size ($\left.2.3 \pm 3.6 \mathrm{~kJ} \cdot \mathrm{kg}^{-1}, \mathrm{p}=0.28, \mathrm{~d}=0.39 ;-18.6 \pm 24.6 \mathrm{~min}, \mathrm{p}=0.19, \mathrm{~d}=0.68\right)$. Body mass increased $1.0 \pm 0.7 \%$ from trial 1 to trial $2(75.6 \pm 10.1$ vs. $76.3 \pm 10.3 \mathrm{~kg}, \mathrm{p}=0.02$, $\mathrm{d}=0.07)$, but was not different in trial 3 compared to trial $1(0.6 \pm 0.9 \% ; 76.0 \pm$ $10.0 \mathrm{~kg}, \mathrm{p}=0.25, \mathrm{~d}=0.04)$.

There were no differences across trials in the amount of work completed at any intensity. However, compared to trial $1\left(7.1 \pm 2.3 \mathrm{~kJ} \cdot \mathrm{kg}^{-1}\right)$ there was a small and moderate increase in high intensity work done at $90 \%$ PPO in trial $2(8.9 \pm 4.7$ $\left.\mathrm{kJ} \cdot \mathrm{kg}^{-1} ; \mathrm{p}=0.30, \mathrm{~d}=0.49\right)$ and $3\left(9.8 \pm 5.8 \mathrm{~kJ} \cdot \mathrm{kg}^{-1} ; \mathrm{p}=0.29, \mathrm{~d}=0.61\right)$, respectively. There was a main effect of trial for peak HR during high intensity (90\% PPO) workloads. Peak HR was lower in trial $3(170.4 \pm 7.1)$ compared to both trial 2 $(174.1 \pm 7.5, \mathrm{p}=0.03, \mathrm{~d}=0.51)$ and trial $1(177.3 \pm 7.3, \mathrm{p}=0.006, \mathrm{~d}=0.96)$. Postexercise blood glucose concentration was not different between trials $(4.1 \pm 0.6$ $\mathrm{mM})$.

Interstitial glucose AUC was different during matched $72 \mathrm{~h}$ periods spaning CHO load 1 and 2. The AUC during CHO load 1 (days 2-4; $390.2 \pm 28.9 \mathrm{mmol} \cdot \mathrm{Lh}^{-}$ ${ }^{1}$ ) was greater than during $\mathrm{CHO}$ load 2 with a small effect size (days 6-8; 376.8 $\pm 31.1 \mathrm{mmol} \cdot \mathrm{Lh}^{-1} ; \mathrm{p}=0.03, \mathrm{~d}=0.45 ;$ Figure 3 ). There were no differences in external load $\left(11.0 \pm 3.4 \mathrm{~kJ} \cdot \mathrm{kg}^{-1}\right)$ or sRPE across all SS cycling bouts $(297.8 \pm 111.3$ 
AU). The mean duration of SS cycling bouts was $75.5 \pm 22.0$ min and the mean workload was $58.3 \pm 3.4 \%$ of PPO $\left(2.5 \pm 0.2 \mathrm{~W} \cdot \mathrm{kg}^{-1}\right)$.

\section{Discussion}

The main findings of this study were that: 1) repeated muscle glycogen supercompensation was achieved with consecutive $4 \mathrm{~d}$ periods of high $\mathrm{CHO}$ feeding; 2) $72 \mathrm{~h}$ interstitial glucose AUC was lower throughout the second $\mathrm{CHO}$ loading period compared to the first CHO load, despite matched dietary intakes; and 3) successive glycogen supercompensation was accompanied by a large increase in exercise work capacity on each occasion.

Our study shows for the first time that back-to-back muscle glycogen supercompensation is possible following exhaustive exercise with $4 \mathrm{~d}$ of high carbohydrate feeding. The data from the present study expand on the previous work from McInerney and colleagues ${ }^{12}$ that show consecutive $2 \mathrm{~d}$ periods of $\mathrm{CHO}$ loading between exhaustive exercise substantially increased muscle glycogen concentration after the first $2 \mathrm{~d} \mathrm{CHO}$ loading period, but failed to promote glycogen supercompensation after the second CHO loading period. Despite the difference in recovery days between studies, the initial glycogen supercompensation was in close agreement, resulting in an increased muscle glycogen content of $\sim 250-280 \mathrm{mmol} \cdot \mathrm{kg}^{-1} \mathrm{DM}$ above normal resting levels. 
However, the contrasting effect on glycogen resynthesis between studies when the high CHO feeding strategy was immediately repeated, indicates interactions between temporal, dietary and physiological factors may affect the capacity for consecutive muscle glycogen supercompensation in relatively short timeframes.

It has been proposed that failure of muscle glycogen stores to repeatedly reach supercompensated levels may be a consequence of the cumulative effect of exhaustive exercise bouts in close succession ${ }^{12}$. For example, acute mechanisms of glycogen resynthesis are purported to include elevated AMPK and glycogen synthase activity ${ }^{18}$. However, glycogen synthase activity appears to be similar with repeated glycogen depletion and carbohydrate loading ${ }^{12}$, and therefore seems unlikely to attenuate glycogen supercompensation under these conditions. The possibility exists that excessive muscle fatigue and/or a priority for muscle repair and remodelling after repeated and prolonged strenuous exercise impairs, at least in part, activation of the cellular mechanisms for glycogen resynthesis, or glucose is utilised for cellular processes rather than glycogen storage ${ }^{19}$; such a hypothesis has been proposed following exercise inducing mechanical muscle damage ${ }^{19}$, but is also plausible following high intensity cycling, given prolonged/intense aerobic exercise is also associated with high rates of protein turnover ${ }^{20}$. Consequently, the $4 \mathrm{~d}$ between exercise to exhaustion in the present study that included two recovery days and a rest day, together with a total CHO intake of $\sim 40 \mathrm{~g} \cdot \mathrm{kg}^{-1}$, may be 
necessary to permit repeated muscle glycogen supercompensation. Whether an impairment in glycogen resynthesis is unique to exhaustive exercise bouts with limited recovery $(<48 \mathrm{~h})$ and whether severe glycogen depletion is a prerequisite for repeated muscle glycogen supercompensation are important questions for future research. A limitation of the present study was the omission of post-exercise muscle biopsies following trials 1 and 2; consequently, the post-exercise muscle glycogen concentrations are not reported. However, based on data from McInerney and colleagues ${ }^{12}$, it is clear that this exercise protocol significantly reduces muscle glycogen, and post-exercise muscle glycogen concentrations in our study were likely $\sim 100 \mathrm{mmol} . \mathrm{kg}^{-1} \mathrm{DM}$. Nonetheless, our data provide support for the practical utility of $\mathrm{CHO}$ loading to elevate muscle glycogen concentrations for enhanced performance capacity in competition ${ }^{8}$, and also provides new information to show repeated glycogen supercompensation is achievable in a $4 \mathrm{~d}$ timeframe, which has important implications for dietary and recovery strategies during congested competition schedules.

Interestingly, despite muscle glycogen supercompensation in response to the consecutive $\mathrm{CHO}$ loading trials, there was a small effect for a lower glucose AUC during the second $\mathrm{CHO}$ load. There are several potential mechanisms to explain such a finding. Firstly, a reduced $\mathrm{CHO}$ absorption at the gastrointestinal tract may be evident, due to an interaction between repeated prolonged exercise bouts that 
may predispose to intestinal epithelial damage ${ }^{21}$, and prolonged exposure to a very high $\mathrm{CHO} /$ energy diet. Indeed, the primary glucose transporter in enterocytes (SGLT1) has the capacity for dynamic change and is highly responsive to altered carbohydrate intake ${ }^{22,23}$. Accordingly, the initial days of high $\mathrm{CHO}$ feeding following trial 1 may have promoted an immediate adaptive response that increased activity of transporters, which abated in response to the arduous exercise and dietary regimens. Second, it is possible the lower glucose AUC may be due to enhanced storage of glycogen in Type II fibres stimulated by the high intensity, exhaustive exercise during trial 1 that may not have been detectable from the glycogen assay. Finally, it's most likely an increased clearance of circulatory glucose is due to greater rates of $\mathrm{CHO}$ oxidation with prolonged exposure to high carbohydrate availability. Goedecke and colleagues ${ }^{24}$ have shown muscle glycogen content is strongly correlated with resting respiratory exchange ratio, and together with Type I muscle fibre content (among other factors) explains $\sim 60 \%$ of the variability in resting respiratory exchange ratio. This phenomenon and the increase in $\mathrm{CHO}$ oxidation routinely reported at rest ${ }^{25}$ and during exercise ${ }^{26}$ with high dietary $\mathrm{CHO}$ intakes likely accounts for the lower whole body glycaemia during the $72 \mathrm{~h}$ period between trials 2 and 3.

The carbohydrate loading protocol in the present study was associated with an increase in total work capacity, and a small-moderate effect for greater work 
performed at 90\% PPO in trials 2 and 3, respectively. Accordingly, our data support the well characterised and beneficial effect of commencing exercise with high muscle glycogen concentration on endurance performance ${ }^{7}$. Indeed, a recent meta-analysis ${ }^{27}$ presents models of muscle glycogen utilisation during exercise of differing intensities and starting glycogen concentrations. Our data support the findings of Areta and Hopkins ${ }^{27}$ showing higher starting glycogen concentration extends time to fatigue during prolonged bouts of endurance exercise. While there was similar high intensity work performed in trial 2 and 3, a marginal reduction in total work capacity was apparent in trial 3 despite comparable starting muscle glycogen. It may be that the repeated priming of muscle with high starting glycogen concentration prior to prolonged exercise predisposed cellular metabolism to greater rates of glycogen utilisation during trial $3^{28}$, resulting in a minor reduction in exercise capacity. In addition, peak heart rate in trial 3 was lower than trials 2 and 1 , which may be indicative of cumulative fatigue/overreaching in participants undertaking a series of exercise bouts to exhaustion $^{29}$. Regardless, in trial 3 participants completed more high intensity work compared to trial 1 , and displayed a similar total work capacity to trial 2 , demonstrating a beneficial effect of $\mathrm{CHO}$ loading to a fatigued athlete.

\section{Conclusion}


Our study provides novel data on the supercompensation of muscle glycogen concentration with a high $\mathrm{CHO}$ intake between repeated bouts of exhaustive exercise. We show that repeated muscle glycogen supercompensation is possible with $4 \mathrm{~d}$ of high $\mathrm{CHO}$ feeding between exhaustive exercise bouts, and that the CHO loading strategy we employed was associated with an increase in the amount of high intensity work performed and superior endurance capacity.

\section{Practical Implications}

- It is possible to repeatedly supercompensate muscle glycogen with $4 \mathrm{~d}$ of high CHO feeding between consecutive bouts of exhaustive exercise.

- Improved high intensity exercise capacity ( 25-30\%) was maintained during "back-to-back" exercise performances, demonstrating beneficial effects associated with effective repeated $\mathrm{CHO}$ loading.

- Practitioners and athletes should carefully consider the dietary and recovery strategy that enables the maintenance of exercise capacity when the competition schedule is congested with limited recovery between matches or events.

\section{Acknowledgements}

We would like to thank the participants for their commitment to this study. The authors would like to thank Brogan Lee for her assistance with dietary preparation 
and data collection, Dr. Robert Fassett (M.D.) for undertaking the muscle biopsy procedures for this study and Mark A. Hearris for his assistance with skeletal muscle glycogen measurement. This research did not receive any specific grant from funding agencies in the public, commercial, or not-for-profit sectors. 


\section{References}

1. Bergstrom J, Hultman E. Muscle glycogen synthesis after exercise: an enhancing factor localized to the muscle cells in man. Nature 1966; 210(5033):309-310.

2. Hultman E, Bergstrom J. Muscle glycogen synthesis in relation to diet studied in normal subjects. Acta Med Scand 1967; 182(1):109-117.

3. Bergstrom J, Hermansen L, Hultman E, Saltin B. Diet, muscle glycogen and physical performance. Acta Physiol Scand 1967; 71(2):140-150.

4. Karlsson J, Saltin B. Diet, muscle glycogen, and endurance performance. J Appl Physiol 1971; 31(2):203-206.

5. van Loon LJ, Greenhaff PL, Constantin-Teodosiu D, Saris WH, Wagenmakers AJ. The effects of increasing exercise intensity on muscle fuel utilisation in humans. J Physiol 2001; 536(Pt 1):295-304.

6. Romijn JA, Coyle EF, Sidossis LS, et al. Regulation of endogenous fat and carbohydrate metabolism in relation to exercise intensity and duration. Am J Physiol 1993; 265(3 Pt 1):E380-391.

7. Rauch LH, Rodger I, Wilson GR, et al. The effects of carbohydrate loading on muscle glycogen content and cycling performance. Int J Sport Nutr 1995; 5(1):25-36.

8. Burke LM, Hawley JA, Wong SH, Jeukendrup AE. Carbohydrates for training and competition. J Sports Sci 2011; 29 Suppl 1:S17-27.

9. Burke LM, van Loon LJC, Hawley JA. Postexercise muscle glycogen resynthesis in humans. J Appl Physiol (1985) 2017; 122(5):1055-1067.

10. Thomas DT, Erdman KA, Burke LM. Position of the Academy of Nutrition and Dietetics, Dietitians of Canada, and the American College of Sports Medicine: Nutrition and Athletic Performance. J Acad Nutr Diet 2016; 116(3):501-528.

11. Richard NA, Koehle MS. Optimizing recovery to support multi-evening cycling competition performance. Eur J Sport Sci 2018:1-13.

12. McInerney P, Lessard SJ, Burke LM, et al. Failure to repeatedly supercompensate muscle glycogen stores in highly trained men. Med Sci Sports Exerc 2005; 37(3):404-411.

13. Bussau VA, Fairchild TJ, Rao A, Steele P, Fournier PA. Carbohydrate loading in human muscle: an improved 1 day protocol. Eur J Appl Physiol 2002; 87(3):290-295.

14. Hawley JA, Noakes TD. Peak power output predicts maximal oxygen uptake and performance time in trained cyclists. Eur J Appl Physiol 1992; 65(1):7983. 
15. Foster C, Florhaug JA, Franklin J, et al. A new approach to monitoring exercise training. J Strength Cond Res 2001; 15(1):109-115.

16. van Loon LJ, Saris WH, Kruijshoop M, Wagenmakers AJ. Maximizing postexercise muscle glycogen synthesis: carbohydrate supplementation and the application of amino acid or protein hydrolysate mixtures. Am J Clin Nutr 2000; 72(1):106-111.

17. Impey SG, Hammond KM, Shepherd SO, et al. Fuel for the work required: a practical approach to amalgamating train-low paradigms for endurance athletes. Physiol Rep 2016; 4(10):e12803.

18. Hingst JR, Bruhn L, Hansen MB, et al. Exercise-induced molecular mechanisms promoting glycogen supercompensation in human skeletal muscle. Molecular Metabolism 2018; 16:24-34.

19. Costill DL, Pascoe DD, Fink WJ, Robergs RA, Barr SI, Pearson D. Impaired muscle glycogen resynthesis after eccentric exercise. J Appl Physiol (1985) 1990; 69(1):46-50.

20. Howarth KR, Phillips SM, MacDonald MJ, Richards D, Moreau NA, Gibala MJ. Effect of glycogen availability on human skeletal muscle protein turnover during exercise and recovery. J Appl Physiol 2010; 109(2):431438.

21. Costa RJS, Snipe RMJ, Kitic CM, Gibson PR. Systematic review: exerciseinduced gastrointestinal syndrome-implications for health and intestinal disease. Aliment Pharmacol Ther 2017; 46(3):246-265.

22. Dyer J, Al-Rammahi M, Waterfall L, et al. Adaptive response of equine intestinal $\mathrm{Na}+$ /glucose co-transporter (SGLT1) to an increase in dietary soluble carbohydrate. Pflugers Arch - Eur J Physiol 2009; 458(2):419-430.

23. Moran AW, Al-Rammahi MA, Arora DK, et al. Expression of Na+/glucose co-transporter 1 (SGLT1) in the intestine of piglets weaned to different concentrations of dietary carbohydrate. Br J Nutr 2010; 104(5):647-655.

24. Goedecke JH, St Clair Gibson A, Grobler L, Collins M, Noakes TD, Lambert EV. Determinants of the variability in respiratory exchange ratio at rest and during exercise in trained athletes. Am J Physiol Endocrinol Metab 2000; 279(6):E1325-1334.

25. Acheson KJ, Schutz Y, Bessard T, Anantharaman K, Flatt JP, Jequier E. Glycogen storage capacity and de novo lipogenesis during massive carbohydrate overfeeding in man. Am J Clin Nutr 1988; 48(2):240-247.

26. Coyle EF, Jeukendrup AE, Oseto MC, Hodgkinson BJ, Zderic TW. Low-fat diet alters intramuscular substrates and reduces lipolysis and fat oxidation during exercise. Am J Physiol Endocrinol Metab 2001; 280(3):E391-398.

27. Areta JL, Hopkins WG. Skeletal Muscle Glycogen Content at Rest and During Endurance Exercise in Humans: A Meta-Analysis. Sports Med 2018. 
28. Hargreaves M, McConell G, Proietto J. Influence of muscle glycogen on glycogenolysis and glucose uptake during exercise in humans. J Appl Physiol 1995; 78(1):288-292.

29. Le Meur Y, Hausswirth C, Natta F, Couturier A, Bignet F, Vidal PP. A multidisciplinary approach to overreaching detection in endurance trained athletes. J Appl Physiol (1985) 2013; 114(3):411-420. 
Figure 1. Study overview. Participants completed a $48 \mathrm{~h}$ and $24 \mathrm{~h}$ period of exercise and dietary standardisation, respectively, prior to completing three intermittent exhaustive cycling trials on days 1,5 and 9. Cycling trials were separated by matched periods (days 2-4 and 6-8) of prescribed training and prepackaged dietary intake. Steady state cycling bouts consisted of 60-90 min of cycling at 58-63\% PPO. $\mathrm{CGM}=$ continuous glucose monitor insertion; $\mathrm{CHO}=$ carbohydrate; SS = steady state.

\begin{tabular}{|c|c|c|c|c|c|c|c|c|c|c|c|}
\hline & Day -2 & Day -1 & Day 1 & Day 2 & Day 3 & Day 4 & Day 5 & Day 6 & Day 7 & Day 8 & Day 9 \\
\hline Exercise & SS cycling & $\begin{array}{c}\text { Rest \& } \\
\text { CGM }\end{array}$ & $\begin{array}{l}\text { Cycling } \\
\text { Trial } 1\end{array}$ & SS cycling & SS cycling & $\begin{array}{c}\text { Rest \& } \\
\text { CGM }\end{array}$ & $\begin{array}{l}\text { Cycling } \\
\text { Trial }\end{array}$ & SS cycling & SS cycling & Rest & $\begin{array}{c}\text { Cycling } \\
\text { Trial 3 }\end{array}$ \\
\hline $\mathrm{CHO}\left(g^{\prime} \mathrm{kg}^{-1} \cdot \mathrm{day}^{-1}\right)$ & Habitual & 5 & 10 & 10 & 10 & 10 & 10 & 10 & 10 & 10 & N/A \\
\hline
\end{tabular}

Figure 2. Effects of repeated $4 \mathrm{~d}$ carbohydrate loading $\left(\sim 10 \mathrm{~g} \cdot \mathrm{kg}^{-1} \cdot \mathrm{day}^{-1}\right)$ on (A) pre-exercise skeletal muscle glycogen concentration (mmol $\cdot \mathrm{kg}^{-1}$ dry mass) and (B) total work capacity $\left(\mathrm{kJ} \cdot \mathrm{kg}^{-1}\right)$ in exhaustive cycling trials 1 (unloaded), 2 and 3 (loaded). Cycling trials were completed on days 1, 5 and 9 of the $9 \mathrm{~d}$ experimental period and consisted of 2 min work intervals (90-60\% peak power output) interspersed with 2 min recovery (40\% peak power output) undertaken to exhaustion. Data were analysed using one-way repeated measures ANOVA with 
Tukey's post-hoc analyses. Grey circles represent individual data points. ${ }^{\text {a Different }}$ from trial $1(\mathrm{p}<0.05) . \mathrm{DM}=$ dry mass.

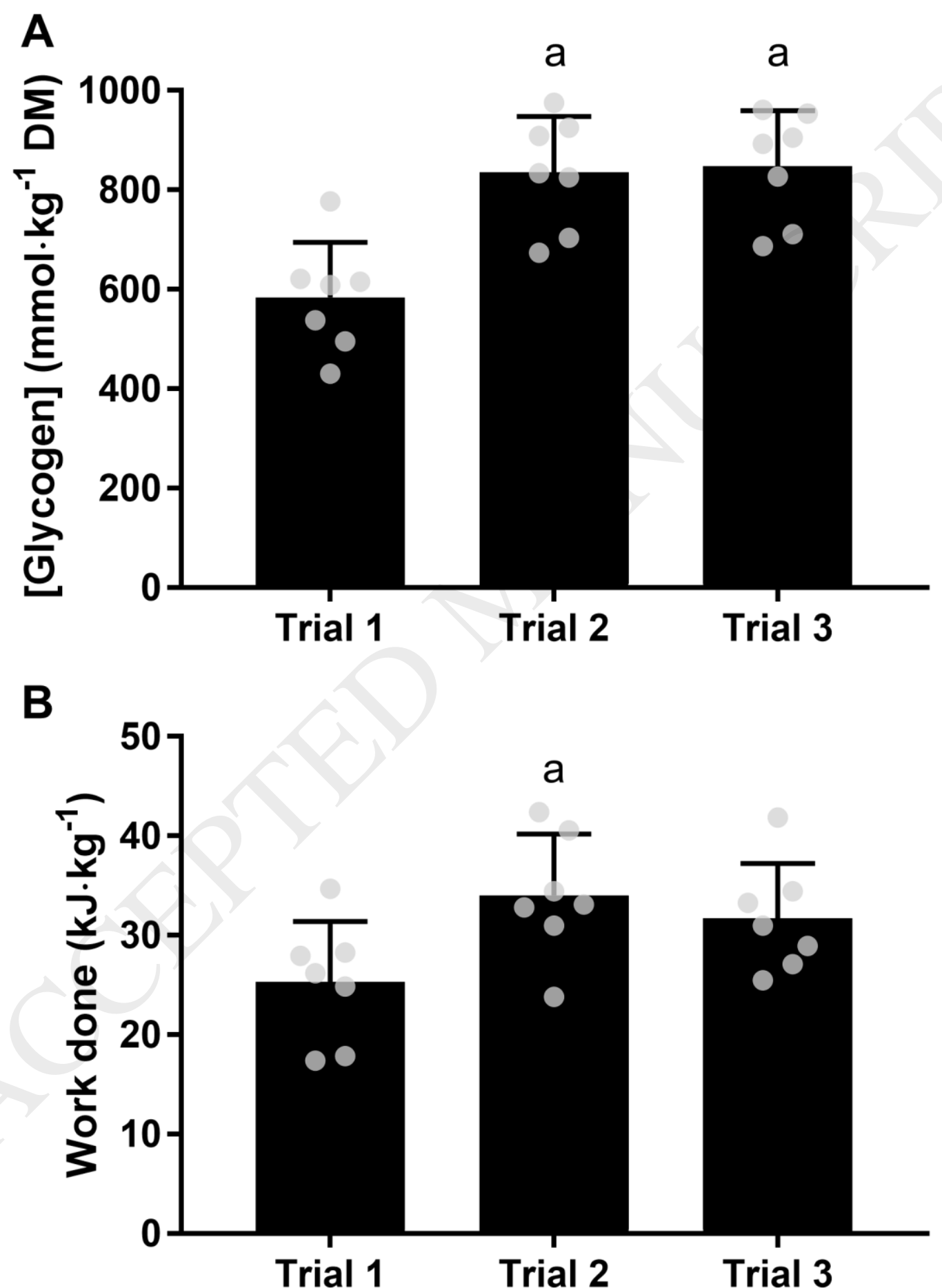


Figure 3. Interstitial glucose area under the curve $\left(\mathrm{mmol} \cdot \mathrm{Lh}^{-1}\right)$ for matched $72 \mathrm{~h}$ periods during carbohydrate load 1 (days 2-4) and 2 (days 6-8). Interstitial glucose was measured continuously throughout the $9 \mathrm{~d}$ experimental period and matched $72 \mathrm{~h}$ periods were analysed using paired samples t-tests $(\mathrm{n}=6)$. Grey circles represent individual data points. ${ }^{a}$ Different from carbohydrate load $1(\mathrm{p}<0.05)$. $\mathrm{AUC}=$ area under the curve.

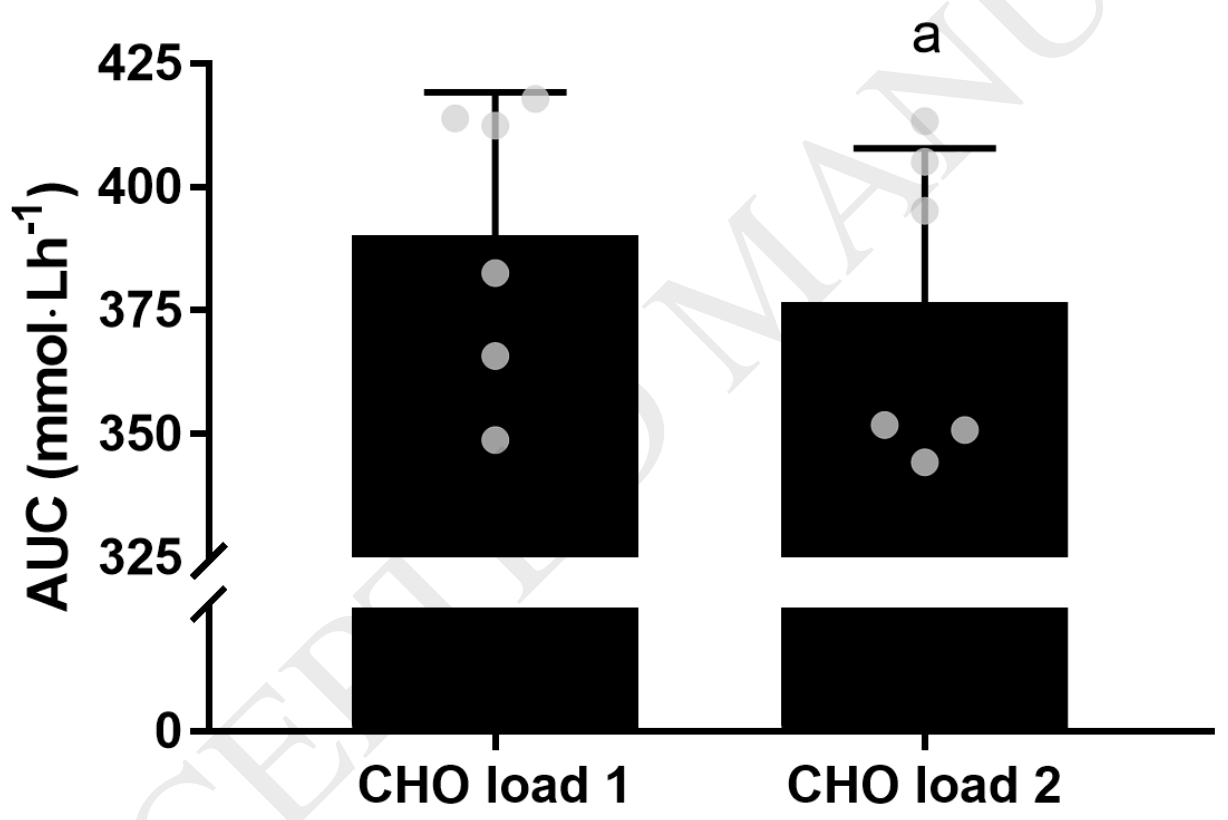

